\title{
ChemComm
}

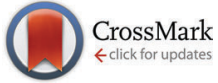

Cite this: Chem. Commun., 2017 53,123

Received 4th November 2016, Accepted 23rd November 2016

DOI: $10.1039 / \mathrm{c} 6 \mathrm{cc} 08836 \mathrm{~h}$

www.rsc.org/chemcomm

\section{Clearing the undergrowth: detection and quantification of low level impurities using ${ }^{19}$ F NMR $\dagger$}

\author{
Pinelopi Moutzouri, ${ }^{a}$ Peter Kiraly, ${ }^{a}$ Andrew R. Phillips, ${ }^{b}$ Steven R. Coombes, ${ }^{c}$ \\ Mathias Nilsson ${ }^{a}$ and Gareth A. Morris ${ }^{\star a}$
}

\begin{abstract}
A new method for the analysis of low level impurities in sparsely fluorinated species allows measurement of clean high dynamic range ${ }^{19} \mathrm{~F}$ spectra, fully decoupled and free of interfering signals from ${ }^{13} \mathrm{C}$ isotopomers.
\end{abstract}

The high sensitivity and wide chemical shift range of ${ }^{19} \mathrm{~F} \mathrm{NMR}^{1-4}$ make it potentially very attractive for characterising fluorinecontaining impurities. In pharmaceutical chemistry, for example, a quarter of current drugs contain one or more fluorines, ${ }^{5}$ and regulatory authorities require all impurities above $0.1 \%$ of a main active pharmaceutical ingredient to be identified and quantified. ${ }^{6}$ Both $1 \mathrm{D}{ }^{19} \mathrm{~F}$ NMR and ${ }^{19} \mathrm{~F}$ DOSY have been used for the detection of minor fluorinated impurities. ${ }^{7}$ One major technical problem is the difficulty of exciting quantitatively the very wide chemical shift range of ${ }^{19} \mathrm{~F}$, but solutions now exist for both $1 \mathrm{D}^{8}$ and $\mathrm{DOSY}^{9}$ experiments. However, there remains the problem of ${ }^{13} \mathrm{C}$ isotopomer signals. At around $0.54 \%$ of the intensity of ${ }^{12} \mathrm{C}$ isotopomer signals, these are in the same range as impurity signals of interest and often have similar chemical shifts, and therefore complicate their identification and quantitation. The obvious solution is to use broadband ${ }^{13} \mathrm{C}$ decoupling to collapse the heteronuclear $J$-couplings. This can work well for ${ }^{1} \mathrm{H}$ spectra, albeit at the expense of some sample heating. ${ }^{10-15}$ However, ${ }^{19} \mathrm{~F}$ is exquisitely sensitive to chemical environment and its large secondary isotope shift means that the decoupled $\left({ }^{19} \mathrm{~F}-{ }^{13} \mathrm{C}\right)$ signals have slightly different chemical shifts from the parent $\left({ }^{19} \mathrm{~F}-{ }^{12} \mathrm{C}\right)$ signals, so decoupling just halves the number of ${ }^{19} \mathrm{~F}-{ }^{13} \mathrm{C}$ signals, rather than hiding them all under the parent. Here we show how to acquire clean ${ }^{19} \mathrm{~F}$ spectra without interference from ${ }^{13} \mathrm{C}$ isotopomers and with no heteronuclear $\left({ }^{1} \mathrm{H}\right.$ or $\left.{ }^{13} \mathrm{C}\right)$ splittings. The new method does

\footnotetext{
${ }^{a}$ School of Chemistry, University of Manchester, Oxford Road,

Manchester M13 9PL, UK. E-mail: g.a.morris@manchester.ac.uk

${ }^{b}$ Pharmaceutical Sciences, AstraZeneca, Silk Road Business Park, Macclesfield, SK10 2NA, UK

${ }^{c}$ Pharmaceutical Technology and Development, AstraZeneca, Silk Road Business Park, Macclesfield, SK10 2NA, UK

$\dagger$ Electronic supplementary information (ESI) available. See DOI: 10.1039/ c6cc08836h
}

not use ${ }^{13} \mathrm{C}$ decoupling, minimising sample heating, and should greatly facilitate the detection and quantification of low-level impurities by ${ }^{19} \mathrm{~F}$ NMR.

Fig. 1 shows ${ }^{19} \mathrm{~F}$ spectra of a slightly degraded sample of rosuvastatin (1, Scheme 1), used for treating dyslipidaemia, spiked with small amounts of precursors 2 and 3. The protondecoupled spectrum of Fig. 1a (multiplet structure renders the proton coupled spectrum, shown in Fig. S4 of the ESI, $\dagger$ uninformative) is complicated by the presence of both one-bond and long-range ${ }^{13} \mathrm{C}$ satellites; one of the two satellite signals due to the presence of ${ }^{13} \mathrm{C}$ at the ortho position with respect to fluorine is almost degenerate with ( $8 \mathrm{ppb}$ from) the signal of 2.

Acquiring a spectrum with this resolution with full broadband decoupling is uncomfortably close to the limits of many instruments, because of the long high-power irradiation required, but if the one-bond ${ }^{13} \mathrm{C}$ satellite signals are suppressed (see Section $\mathrm{S} 1$ of the ESI $\dagger$ ), low power irradiation can be used to decouple the remaining longer-range ( $\geq$ two-bond) couplings. This gives the spectrum of Fig. $1 \mathrm{~b}$, in which a singlet signal is seen for the $2.2 \%$ of ortho- ${ }^{13} \mathrm{C} 1$. Had full ${ }^{13} \mathrm{C}$ decoupling been used, the ipso ${ }^{-13} \mathrm{C}$ signal of $\mathbf{1}$, midway between the one-bond satellites in Fig. 1a, would have been degenerate with that of impurity 1a (a diastereomer). In the spectrum of Fig. 1c, in contrast, which was obtained with the new method, no resolvable signals at all are seen from ${ }^{13} \mathrm{C}$ isotopomers, and there is no interference with the signals of the minor components of the sample.

The new method, using the pulse sequence of Fig. 2, is compatible with several different hardware configurations; the results shown here used a single high band radiofrequency (RF) amplifier and a $\left({ }^{1} \mathrm{H} /{ }^{19} \mathrm{~F}\right),{ }^{13} \mathrm{C}$ triple-resonance probe with a double-tuned high band coil. The experiment consists of three parts: a low-pass filter to suppress one-bond ${ }^{13} \mathrm{C}$ satellite signals; a $J_{\mathrm{CF}}-$ modulated spin echo; and time-shared acquisition during which the ${ }^{19} \mathrm{~F}$ signal is recorded under ${ }^{1} \mathrm{H}$ decoupling.

The low-pass $J$ filter, ${ }^{16-20}$ which converts ${ }^{19} \mathrm{~F}$ antiphase signals into unobservable heteronuclear multiple quantum coherences when $\Delta=1 /\left(2{ }^{1} J_{\mathrm{CF}}\right)$, suppresses the one-bond ${ }^{13} \mathrm{C}$ satellite signals. Since a ${ }^{19} \mathrm{~F}$ spin echo is needed to refocus the 


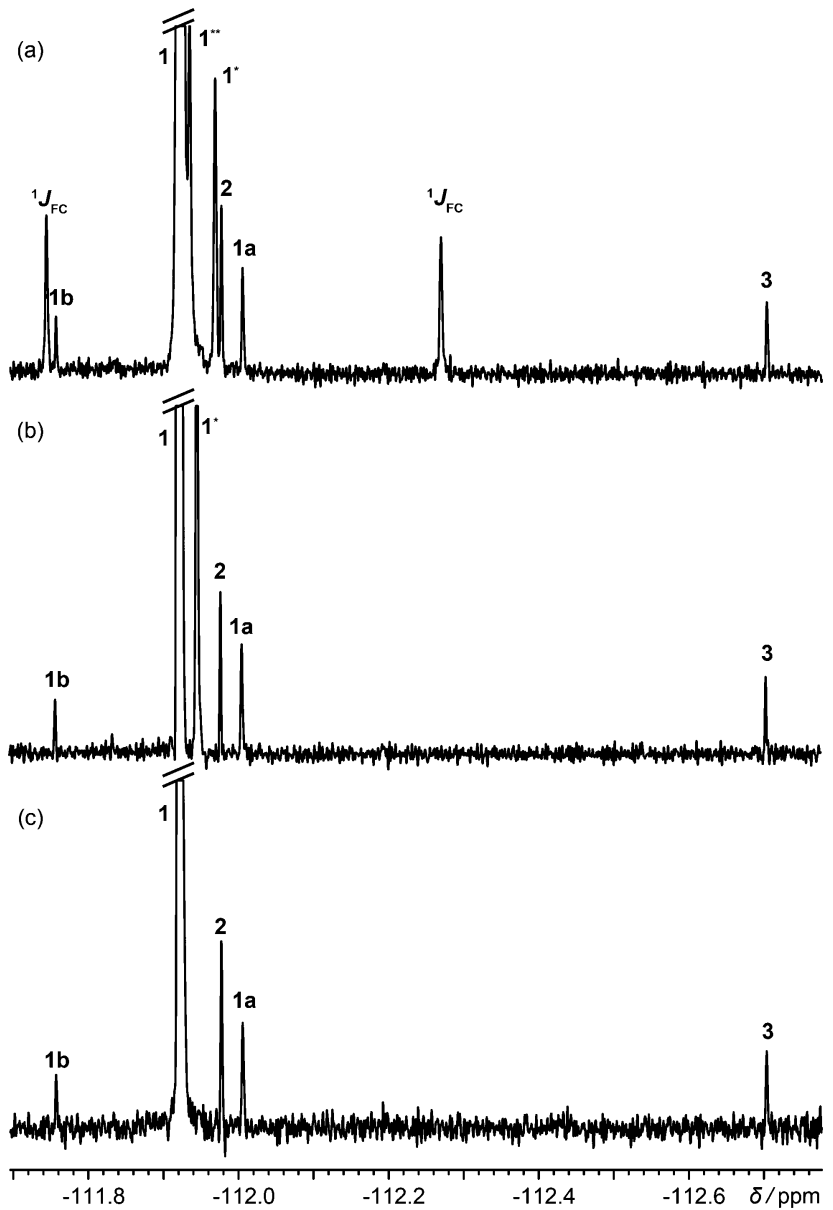

Fig. 1 (a) ${ }^{1} \mathrm{H}$ decoupled ${ }^{19} \mathrm{~F}$ spectrum; (b) ${ }^{1} \mathrm{H}$ decoupled ${ }^{19} \mathrm{~F}$ spectrum acquired with the pulse sequence of Fig. S1a of the ESI, $\dagger$ with one-bond satellites filtered out and long-range couplings decoupled; (c) ${ }^{1} \mathrm{H}$ decoupled, ${ }^{13} \mathrm{C}$ isotopomersuppressed ${ }^{19} \mathrm{~F}$ spectrum acquired with the pulse sequence of Fig. 2. Assignments are shown for rosuvastatin (1), its ipso, ortho and meta ${ }^{13} \mathrm{C}$ isotopomers $\left({ }^{1} J_{C F}, 1^{*}\right.$ and $\left.1^{\star *}\right), \operatorname{BEM}(\mathbf{2}), \mathrm{DPPO}(\mathbf{3})$, a diastereomeric impurity of $\mathbf{1}(\mathbf{1 a})$, and a degradation product (1b). All spectra used the same acquisition time of $13.5 \mathrm{~h}$<smiles>CC(=O)N(C)c1nc(-c2ccc(F)cc2)c(/C=C/[C@@H](O)C[C@H](O)CC(=O)O)c(C(C)C)n1</smiles>

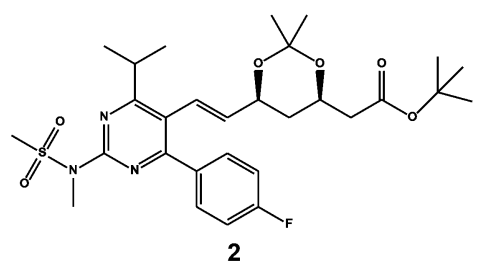

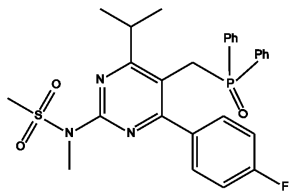

3

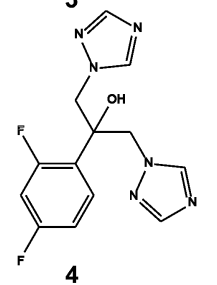

Scheme 1 Rosuvastatin (1), two of its precursors, BEM (2) and DPPO (3), and fluconazole (4).

fluorine chemical shift, there is time to use two ${ }^{13} \mathrm{C} 90^{\circ}$ pulses in a two-stage filter; if a wide range of ${ }^{1} J_{\mathrm{CF}}$ values is present, further stages can be added.

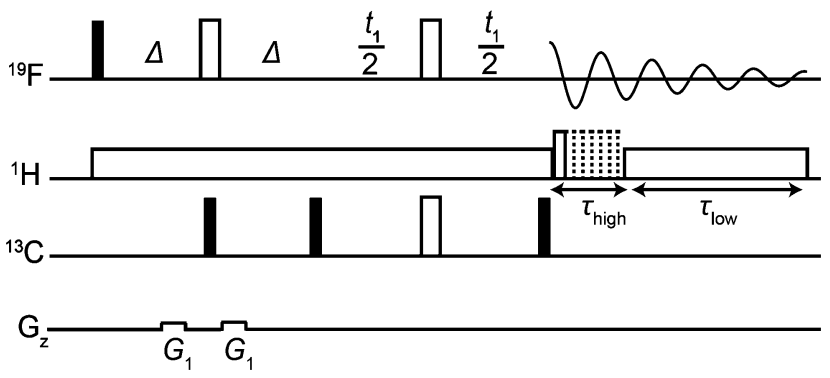

Fig. 2 ODYSSEUS (optimal decoupling yielding satellite suppression-edited ultraclean spectra) pulse sequence for the acquisition of ${ }^{1} \mathrm{H}$ decoupled, ${ }^{13} \mathrm{C}$ isotopomer-suppressed ${ }^{19} \mathrm{~F}$ spectra. Closed narrow rectangles represent $90^{\circ}$ hard RF pulses, and open wide rectangles $180^{\circ}$ hard RF pulses. The delay $\Delta$ is set to $1 /\left(2^{1} J_{\mathrm{FC}}\right)$. Adiabatic bilevel ${ }^{1} \mathrm{H}$ decoupling during time-shared acquisition uses two types of WURST pulse with different durations and amplitudes. In systems with ${ }^{19} \mathrm{~F}-{ }^{19} \mathrm{~F}$ coupling, both $180^{\circ}{ }^{19} \mathrm{~F}$ pulses should be selective. Further experimental details are given in the Experimental section of the ESI. $\dagger$

The modulated spin echo, which is analogous to a heteronuclear $2 \mathrm{D} J$ resolved experiment, ${ }^{21-23}$ makes the phases of the remaining ${ }^{13} \mathrm{C}$ satellite signals depend on the evolution time $t_{1}$, while the desired signals from the ${ }^{12} \mathrm{C}$ isotopomers are unaffected. Weighted averaging of experiments with different $t_{1}$ cancels the modulated signals, leaving a clean spectrum. In practice the most effective way to perform this averaging is by double Fourier transformation and integral projection onto $F_{2}$ of the $F_{1}$ range spanned by the lineshape of the parent signal. This suppresses all satellite signals that would be resolvable in the 1D spectrum, while preserving the quantitative character of the spectrum. The final ${ }^{13} \mathrm{C} 90^{\circ}$ pulse deals with the problem of the phasetwist lineshape ${ }^{24-26}$ of a $2 \mathrm{D} J$ spectrum by suppressing the sine-modulated dispersive part of the signal. The remaining cosine-modulated signal can then be selected by zeroing the imaginary component after the first Fourier transformation, leading to signals that are doubled in $F_{1}$ but have 2D absorption mode lineshapes. The choice of increment $1 / \mathrm{sw} 1$ in $t_{1}$ is determined by the range of couplings to be suppressed (sw1 $>{ }^{n} J_{\mathrm{CH}}$ ), and the number of increments ni by the $T_{2}$ of the parent signal (ni $>\operatorname{sw} 1 T_{2}$ ). Relaxation losses during $t_{1}$ lead to a small sensitivity penalty for the new method, about a factor of 2 here (apparent on comparing Fig. 1a and c).

The data acquisition section of the pulse sequence uses time-shared decoupling because the ${ }^{1} \mathrm{H}$ and ${ }^{19} \mathrm{~F}$ channels share the same coil in the probe used. In normal circumstances, a simple WALTZ $^{27,28}$ or similar decoupling waveform would suffice to decouple ${ }^{1} \mathrm{H}$ from ${ }^{19} \mathrm{~F}$, but the very high dynamic range of the sample means that the weak systematic signal modulations such methods induce would here give rise to significant decoupling sidebands (see Fig. S3, ESI $\dagger$ ). These are suppressed very effectively here by the use of bilevel adiabatic decoupling. ${ }^{29}$

As well as decoupling ${ }^{1} \mathrm{H}$ from ${ }^{19} \mathrm{~F}$ during acquisition, it can be helpful to decouple in the earlier parts of the sequence, to suppress any echo modulation caused by strong ${ }^{1} \mathrm{H}^{-1} \mathrm{H}$ coupling. This is common in aromatic spin systems (as for example in Fig. S2 of the ESI $\dagger)^{21,30,31}$ Here the quality of decoupling is less critical, so bilevel decoupling is not needed. 
Table 1 Expected and measured relative percentages of components 2, 3 and impurity $\mathbf{1 a}$ as percentages of $\mathbf{1}$, for a fresh sample lacking degradation product $\mathbf{1 b}$

\begin{tabular}{lll}
\hline & Expected (\%) & Measured (\%) \\
\hline $\mathbf{2}$ & 0.33 & $0.37 \pm 0.03$ \\
3 & 0.17 & $0.18 \pm 0.03$ \\
1a & 0.28 & $0.26 \pm 0.03$
\end{tabular}

Fig. S5 (ESI $\dagger$ ) shows the intermediate stage in the production of Fig. 1c at which the $F_{2}$ projection of the $2 \mathrm{D}$ is calculated. Each ${ }^{13} \mathrm{C}$ isotopomer gives four symmetrically-disposed signals, with frequency coordinates $\left( \pm J_{\mathrm{CF}} / 2, \delta \pm J_{\mathrm{CF}} / 2\right)$; in Fig. S5 (ESI $\dagger$ ) both of the less shielded satellites overlap in $F_{2}$ with $t_{1}$-noise from the parent peak. Integration between the dotted lines produces the spectrum of Fig. 1c.

To test the quantification performance of the new method, the relative percentages of the impurities compared to the main drug substance were measured using the spectrum (Fig. S6 of the ESI $\dagger$ ) of a fresh, undegraded, sample. Since the dynamic range of the spectrum is very high, lineshape fitting ${ }^{32-36}$ was used instead of conventional integration. As shown in Table 1, the relative percentages measured agree well with those expected.

In systems with mutually coupled fluorines, homonuclear $J$ modulation interferes with ${ }^{13} \mathrm{C}$ satellite suppression if hard $180^{\circ}{ }^{19} \mathrm{~F}$ pulses are used in Fig. 2. Selective $180^{\circ}$ pulses avoid this problem, as shown in Fig. 3 for the antifungal drug fluconazole, which has $J_{\mathrm{FF}}=$ 8.1 Hz. Fig. $3 \mathrm{~b}$ and $\mathrm{c}$ were acquired separately using the selective analogue of Fig. 2 to excite the regions around -107 and $-111 \mathrm{ppm}$ respectively, revealing the degradation products $\mathbf{4 a}, \mathbf{4 b}$ and $\mathbf{4 c}$.

${ }^{13} \mathrm{C}$ isotopomer signals can pose significant challenges in identifying and quantifying impurities down to the $0.1 \%$ level. The novel approach introduced here of filtering out, rather than decoupling, these signals offers the possibility of acquiring clean, high dynamic range ${ }^{19} \mathrm{~F}$ spectra without interference from species containing ${ }^{13} \mathrm{C}$. A slightly simpler approach can be used in proton spectra.
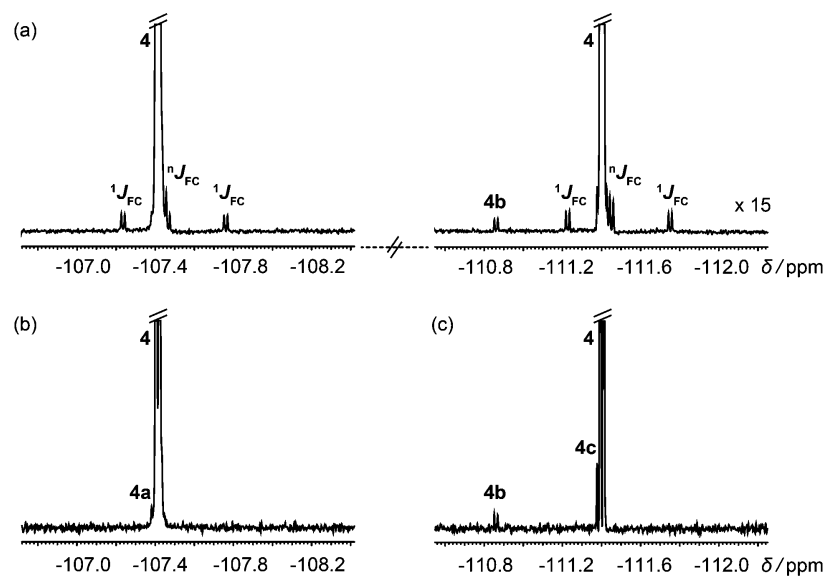

Fig. 3 (a) ${ }^{1} \mathrm{H}$ decoupled ${ }^{19} \mathrm{~F}$ spectrum of a degraded sample of the antifungal drug fluconazole (4); (b and $\mathrm{c}){ }^{1} \mathrm{H}$ decoupled, ${ }^{13} \mathrm{C}$ isotopomersuppressed ${ }^{19} \mathrm{~F}$ spectra acquired separately for each parent signal using the pulse sequence of Fig. 2 with selective ${ }^{19} \mathrm{~F} 180^{\circ}$ pulses.
This work was supported by AstraZeneca and by the Engineering and Physical Sciences Research Council (grant number EP/ N033949/1). All raw experimental data, and the pulse sequence code, can be downloaded from DOI: 10.15127/1.304823.

\section{Notes and references}

1 S. Trefi, V. Gilard, S. Balayssac, M. Malet-Martino and R. Martino, J. Pharm. Biomed. Anal., 2008, 46, 707-722.

2 J. C. Lindon and I. D. Wilson, eMagRes, John Wiley \& Sons, Ltd, 2007, DOI: $10.1002 / 9780470034590 . e m r s t m 1479$.

3 S. Trefi, V. Gilard, M. Malet-Martino and R. Martino, J. Pharm. Biomed. Anal., 2007, 44, 743-754.

4 W. He, F. Du, Y. Wu, Y. Wang, X. Liu, H. Liu and X. Zhao, J. Fluorine Chem., 2006, 127, 809-815.

5 J. Wang, M. Sánchez-Roselló, J. L. Aceña, C. del Pozo, A. E. Sorochinsky, S. Fustero, V. A. Soloshonok and H. Liu, Chem. Rev., 2014, 114, 2432-2506.

$6 \mathrm{ICH}$, Impurities in new drug substances Q3A (R2) International Conference on Harmonisation, IFPMA, Geneva, Switzerland, 2006.

7 N. Mistry, I. M. Ismail, R. Duncan Farrant, M. Liu, J. K. Nicholson and J. C. Lindon, J. Pharm. Biomed. Anal., 1999, 19, 511-517.

8 J. E. Power, M. Foroozandeh, R. W. Adams, M. Nilsson, S. R. Coombes, A. R. Phillips and G. A. Morris, Chem. Commun., 2016, 52, 2916-2919.

9 J. E. Power, M. Foroozandeh, P. Moutzouri, R. W. Adams, M. Nilsson, S. R. Coombes, A. R. Phillips and G. A. Morris, Chem. Commun., 2016, 52, 6892-6894.

10 A. J. Shaka, P. B. Barker and R. Freeman, J. Magn. Reson., 1985, 64, 547-552.

11 T. Fujiwara, T. Anai, N. Kurihara and K. Nagayama, J. Magn. Reson., Ser. A, 1993, 104, 103-105.

12 R. Fu and G. Bodenhausen, Chem. Phys. Lett., 1995, 245, 415-420.

13 L. S. Simeral, Appl. Spectrosc., 1995, 49, 400-402.

14 E.. Kupče and R. Freeman, Chem. Phys. Lett., 1996, 250, 523-527.

15 R. Freeman and E. Kupče, NMR Biomed., 1997, 10, 372-380.

16 A. Bax, R. H. Griffey and B. L. Hawkins, J. Magn. Reson., 1983, 55, 301-315.

17 A. Bax and M. F. Summers, J. Am. Chem. Soc., 1986, 108, 2093-2094.

18 H. Kogler, O. W. Sørensen, G. Bodenhausen and R. R. Ernst, J. Magn. Reson., 1983, 55, 157-163.

19 L. Müller, J. Am. Chem. Soc., 1979, 101, 4481-4484.

20 N. T. Nyberg and O. W. Sørensen, Magn. Reson. Chem., 2006, 44, 451-454.

21 G. Bodenhausen, R. Freeman, G. A. Morris and D. L. Turner, J. Magn. Reson., 1977, 28, 17-28.

22 G. Bodenhausen, R. Freeman, R. Niedermeyer and D. L. Turner, J. Magn. Reson., 1976, 24, 291-294.

23 L. Müller, A. Kumar and R. R. Ernst, J. Magn. Reson., 1977, 25, 383-390.

24 P. Bachmann, W. P. Aue, L. Müller and R. R. Ernst, J. Magn. Reson., 1977, 28, 29-39.

25 A. Bax, A. F. Mehlkopf and J. Smidt, J. Magn. Reson., 1979, 35, 373-377.

26 R. Freeman, S. P. Kempsell and M. H. Levitt, J. Magn. Reson., 1979, 34, 663-667.

27 A. J. Shaka, J. Keeler, T. Frenkiel and R. Freeman, J. Magn. Reson., 1983, 52, 335-338.

28 A. J. Shaka, J. Keeler and R. Freeman, J. Magn. Reson., 1983, 53, 313-340.

29 Ē. Kupče, R. Freeman, G. Wider and K. Wüthrich, J. Magn. Reson., Ser. A, 1996, 122, 81-84.

30 R. Freeman, G. A. Morris and D. L. Turner, J. Magn. Reson., 1977, 26, 373-378.

31 A. Kumar and R. R. Ernst, Chem. Phys. Lett., 1976, 37, 162-164.

32 M. Ala-Korpela, Y. Hiltunen, J. Jokisaari, S. Eskelinen, K. Kiviniitty, M. J. Savolainen and Y. A. Kesäniemi, NMR Biomed., 1993, 6, 225-233.

33 Y. Hiltunen, M. Ala-Korpela, J. Jokisaari, S. Eskelinen, K. Kiviniitty, M. Savolainen and Y. A. Kesäniemi, Magn. Reson. Med., 1991, 21, 222-232.

34 V. V. Mihaleva, S. P. Korhonen, J. van Duynhoven, M. Niemitz, J. Vervoort and D. M. Jacobs, Anal. Bioanal. Chem., 2014, 406, 3091-3102.

35 H. M. Parsons, C. Ludwig and M. R. Viant, Magn. Reson. Chem., 2009, 47, S86-S95.

36 P. Soininen, J. Haarala, J. Vepsäläinen, M. Niemitz and R. Laatikainen, Anal. Chim. Acta, 2005, 542, 178-185. 